\section{ON SITE RESUSCITATION SIMULATION - THE RESULTS OF PARTICIPANTS SURVEY}

Minca Mramor, Mojca Grošelj Grenc, Division of Paediatrics, University Medical Centre Ljubljana, Bohoričeva 20, 1000 Ljubljana

Purpose: To evaluate the participants experience involved in on-site resuscitation simulation and get feedback before implementing more sophisticated simulations (unannounced and film recorded).

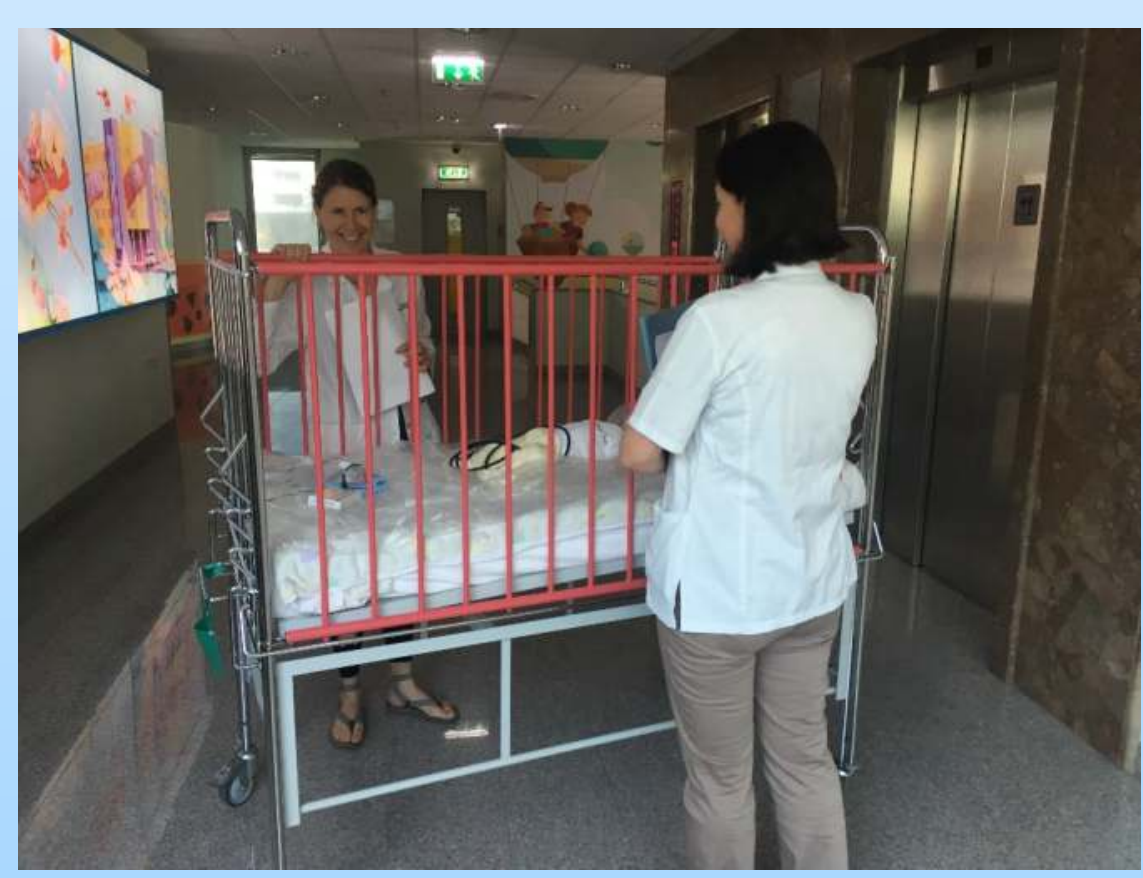

Methods: We performed 10 mock codes simulations of paediatric resuscitation at different departments of the Division of Paediatrics, University Medical Centre Ljubljana. We spent 30 minutes for simulation and 30 minutes for feedback on average. At the end of each session, all participants completed a questionnaire regarding their background, their satisfaction with the simulation and future preferences about simulations.

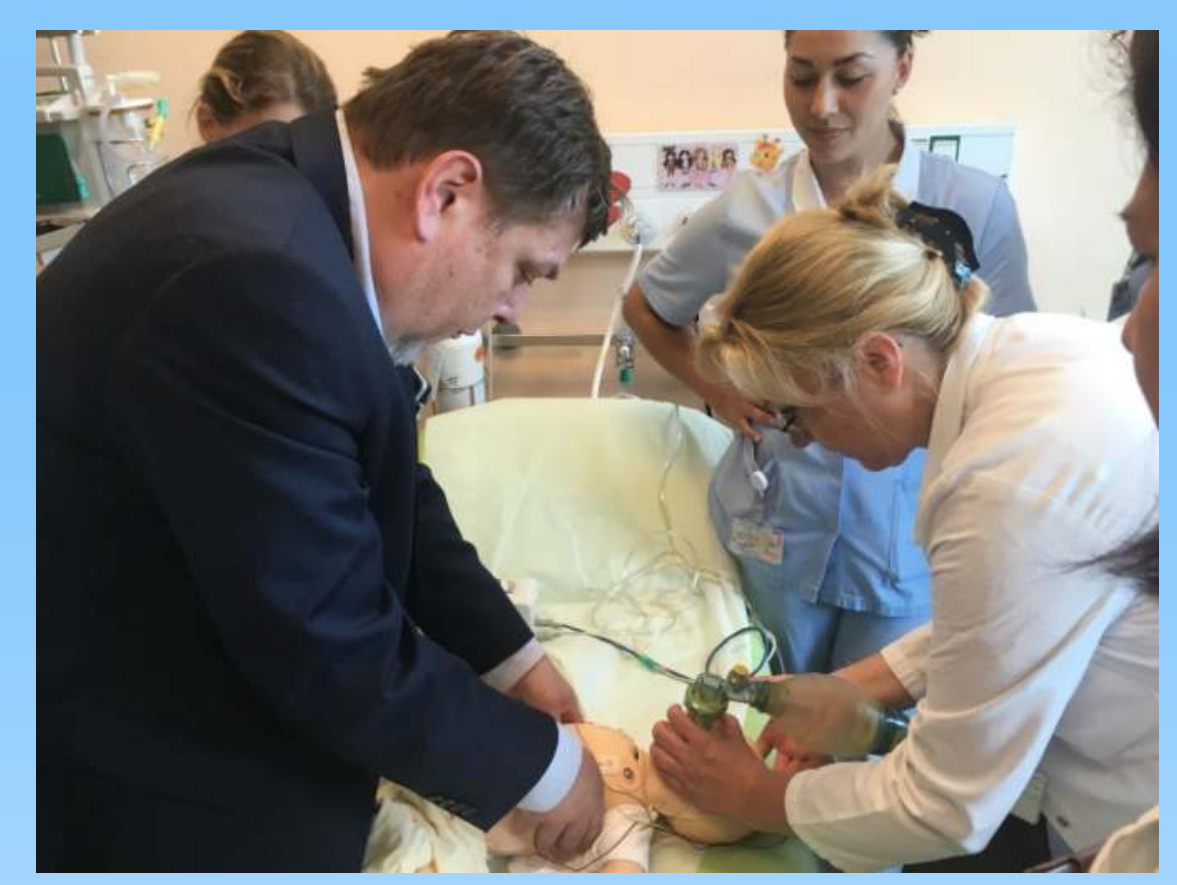

Results: Sixty-two participants completed the questionnaire. The majority were $36-50$ years old $(44 \%)$. The participants' background was: $40 \%$ nurses, $42 \%$ paediatric specialists, $13 \%$ residents, and $5 \%$ others. Almost half of the participants $(42 \%)$ attended a resuscitation course in the last year, $32 \%$ in the last $1-3$ years, and $26 \%$ more than 3 years ago. Nine of ten participants found resuscitation simulations very important for their job position, $8 \%$ thought they are important, only 1 participant assessed them as not very important and nobody found them unimportant.

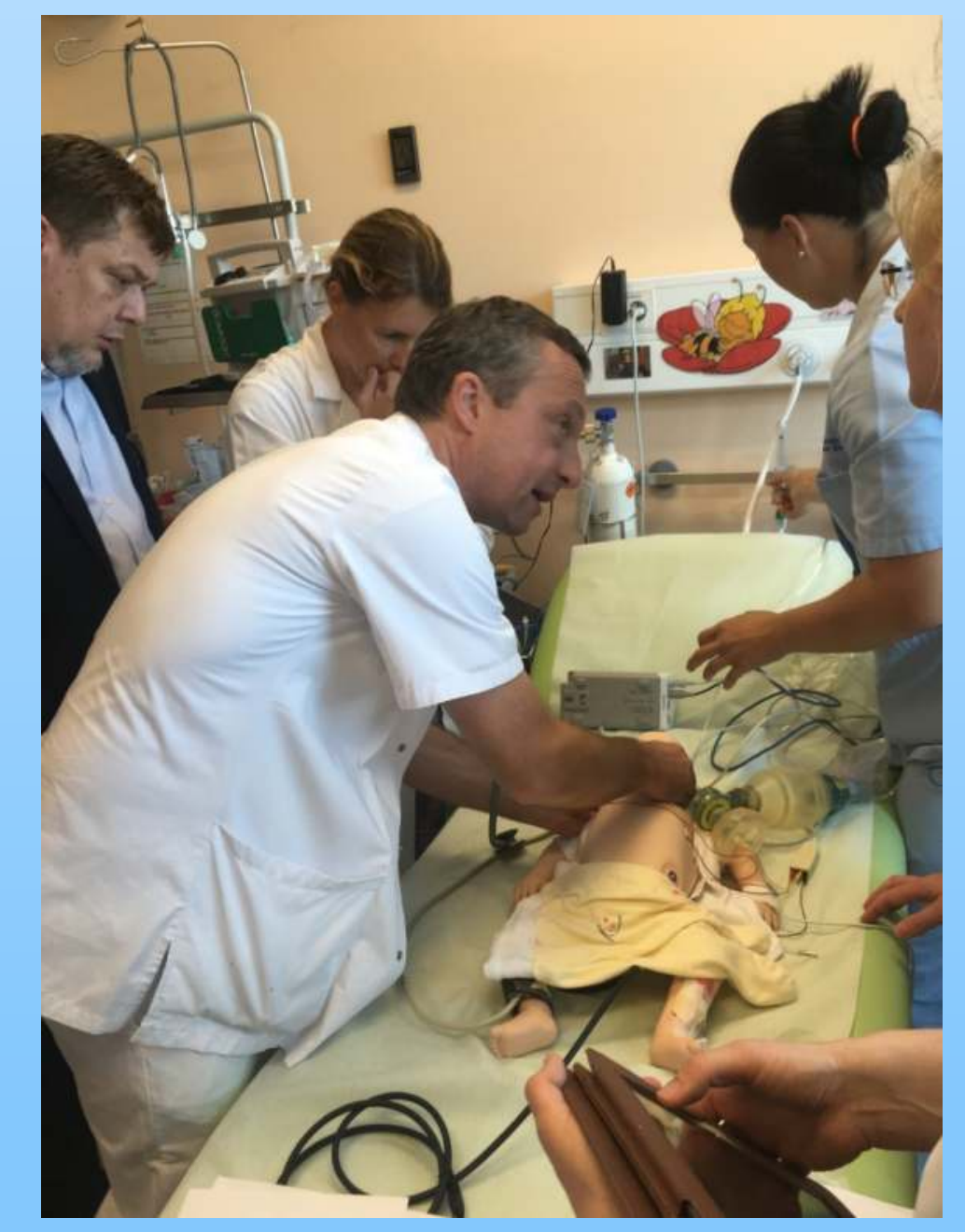

The majority of the participants (57\%) would like to have simulation every 6 months. Nobody found simulation as pressure or load $61 \%$ prepared in advance for announced simulation and $32 \%$ where motivated by the simulation to upgrade their knowledge. Figure shows the quality of the simulations as graded by the participants.
Conclusions: Recent studies have shown that the benefits of simulation training are unequivocal. Furthermore, the results of our survey show that medical personnel find such training important and enjoyable $(1,2)$.
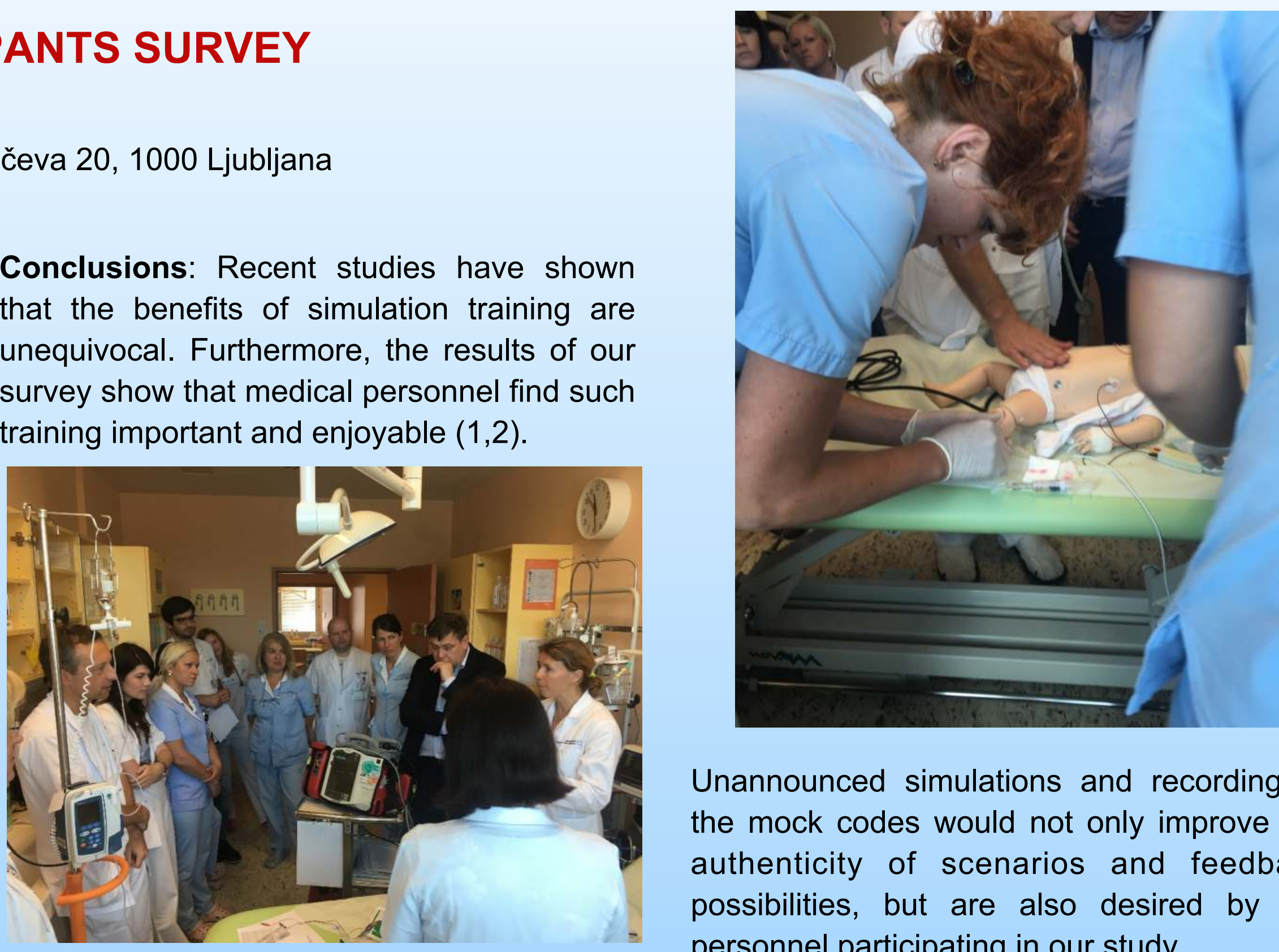

Unannounced simulations and recording of the mock codes would not only improve the authenticity of scenarios and feedback possibilities, but are also desired by the personnel participating in our study.

Figure. The quality of the simulations graded by the participants.

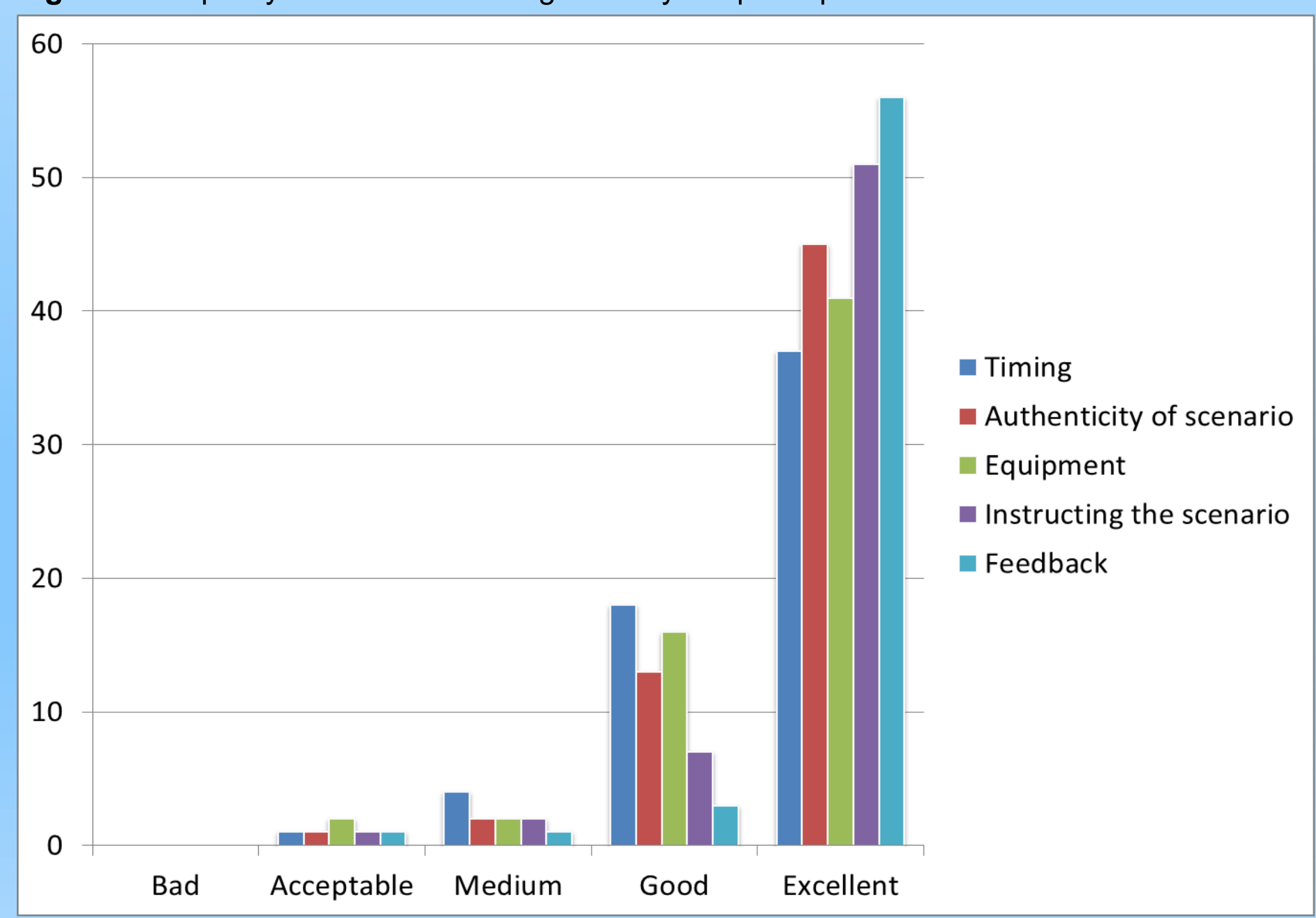

